\title{
11. Looping to success (and failure): second-order mechanisms and policy outcomes
}

\author{
Mallory E. Compton and Paul 't Hart
}

\section{INTRODUCTION}

Significant accomplishments of public policy successes are not always - or even rarely - noticed and appreciated for what they are. Much of the Dutch population lives happily and safely well below sea level, Brazil leads the world in tackling poverty and inequality, and Botswana has avoided the resource curse against all odds. In each case, smartly designed, well-executed, broadly supported and continuously evolving public policy programs make this happen. In this chapter, we examine how second-order mechanisms can remake political and social institutions to reinforce performance and contribute to the success of public policies. In doing so, we assume that public policy analysis and design necessitates a dynamic perspective, that policy processes unfold over time, and that temporality is an essential aspect of explanatory public policy theory.

The study of success in public policy has been a modest affair compared to ongoing efforts to expose public policy failures and scandals and the inherent pathologies of government (Bovens and 't Hart, 1996, 2016; Hall, 1982; King and Crewe, 2014; Peirce, 1981; Schuck, 2014). The stubborn few who insist on studying public policy achievements have mainly focused on conceptualizing what "success" looks like in the complex contentious endeavor that is a public policy, program, or project. Scholars have advanced frameworks for assessing typologies and scales of success in real cases. This work enabled analysts to progress beyond the elegant but oversimplified emphasis on goal achievement that dominated classic program evaluation methodologies and the analytical vagaries of subsequent constructivist and goal-free approaches to evaluation (Bovens, 't Hart and Peters, 2001; McConnell, 2010). What this line of research has yet to deliver, however, is a robust framework explaining differential performance of otherwise similar policy endeavors, though it has 
certainly generated initial hypotheses (see also Glazer and Rothenberg, 2001; Patashnik, 2008). To our knowledge, there has been no systematic attempt to identify the role of social mechanisms in the achievement, consolidation, and reproduction of policy successes.

This is a remarkable omission. Public policy outcomes successful or otherwise materialize through dynamic processes, building and unfolding over time. It seems obvious, then, that in explaining policy outcomes at any given time $t$, an appropriately dynamic perspective should be taken. Focus should be put on specifying mechanisms driving those outcomes realized since time $t-1$. That said, in a parallel universe, historical-institutionalist research on feedback in policy regimes has identified a host of mechanisms affecting not just policy outcomes but - over time and through dynamic loops - the degree of stability and change of these policy regimes themselves (see, for example, Jacobs and Weaver, 2015; Jordan and Matt, 2014; Pierson, 1993; Weaver, 2010). In this chapter, we seek to contribute to the study of policy success by borrowing from this subfield, which has not concerned itself with evaluative questions about success or failure but rather with explaining stability and change in public policy over time. Both the policy success and a policy dynamics perspective can be used to illuminate questions about public policy design and management that hitherto dominant "textbook" models of public policy (e.g., the policy cycle, multiple streams, advocacy coalitions, and punctuated equilibrium frameworks; Peters, 2015; Sabatier and Weible, 2014) overlook or obscure. By combining the two, we gain insight into the interconnections between (dynamic) mechanisms and policy outcomes.

\section{(SECOND-ORDER) MECHANISMS IN PUBLIC POLICY ${ }^{1}$}

In their critique of historical institutionalism, Peters, Pierre and King (2005, p. 1284) argue that identifying systematic patterns between social phenomena is not sufficient, and "to be effective a theory should be capable of linking outcomes with actors and with the process that produced the outcomes." In other words, acceptable explanation must link cause and effect through a social process and avoid "black box" associations (Hedström and Swedberg, 1996). Studies of policy change are also critiqued for struggling to specify mechanisms capable of explaining the magnitude of observed change (for example, consider Givel, 2010; Howlett and Rayner, 2006).

In spite of a growing literature on feedback dynamics, accounts of causation in social and political life remain a niche enterprise (Ayres, 2014; Cavana and Mares, 2004; Collander and Kupers, 2014; De Roo, van Wezemael and Hillier, 2012; Jervis, 1997). Even within literature on the unintended consequences of public policy, a linear causal relation is the default option for understanding outcomes (Ayres, 2014; Van der Steen et al., 2013). There are good reasons for 
this. In stable and bounded systems, the linear causal model is a suitable way to establish a relation between cause and effect, and accordingly assign success and failure to clearly demarcated moments in time and specific actions taken by actors in those moments (Collander and Kupers, 2014). Outside this context, however, in unstable or complex systems (which would characterize any contemporary policy program), the linear perspective presents two shortcomings.

First, a linear causal model does not take into account interactive dynamics. Interventions have multiple effects that are not limited to the designated target or time period. The linear perspective assumes the causal effect of $A$ to be bounded to $B$. However, in complex systems it is difficult to project beforehand where effects will "go," how many mechanisms will be activated, how long effects will resonate, and who will respond to activators. What is called an "unexpected outcome" from the linear view on causality (Sieber, 1981, p. 10) can be understood or even expected from the perspective of interactive complexity. Policies activate more than one social mechanism, with multiple and interactive effects materializing on different time scales. Policy $A$ may affect outcome $B$, but it may also affect outcome $C$ and $B$, and the magnitude or direction of those effects may be conditional on values of other variables in the system.

Second, and relatedly, the linear perspective on causation hardly takes into account reflexivity, or the learning capacity of agents. When policy is added to a system, agents learn from what happens (this is an example of effect multiplicity). Over time they will change their response to stimuli. What seemed to work the first time likely plays out differently the next because the previous intervention changed the system; it instigated learning and agents may adapt their behavior(s) as a result. Causation is a dynamic interactive process that evolves over time, rather than a fixed, stable and almost a-temporal relation between cause and effect. Paying attention to social mechanisms is key to overcoming the limitations of the linear view. Specifying mechanisms better equips theory to explain and anticipate interactive or multi-level effects, or effect multiplicity, including evolution of capacities and interests as policies take their course over time.

To explain the occurrence of policy outcomes we must look beyond linear and fixed mechanisms of cause and effect and adopt a lens of causality that accounts for dynamics in the system (Leeuw, 2008). Therefore, we apply the lens of circular causality to the study of policy success and look at causal loops. Circular causality originated in the literature on system dynamics and cybernetics, and has since been applied to the context of policy and system analysis (Cavana and Mares, 2004; Chapman, 2004; Deutsch, 1963; Forrester, 1961; Haraldsson, 2000; Laitin and Wildavsky, 1988; Maani and Cavana, 2000; Perrow, 1984; Steinbruner, 1974). Central to this approach is the interconnectedness of elements and the feedback mechanisms that shape the interactions between them. With this view, outcomes are seen as the effects 
of interrelated interactions between different actors and factors of the system (Richardson, 1991; Richmond, 1993).

Actions generate feedback in social systems, which becomes input for others, and these feedback loops create patterns, which can be conceptualized in the form of loops (Merali and Allen, 2011). Scholars have discerned a few fundamental types of causal loops. Some loops are self-balancing, others display a self-reinforcing pattern: a change in one factor enforces a loop that leads to a magnification of the original effect (Haraldsson, 2000; Lane, 2008; Maruyama, 1963; Richardson, 1986; Senge, 1990; Toole, 2005). Some loops draw the system towards an outcome intended by the policy-maker - a virtuous cycle - while others - vicious cycles - pull it further away from the original aims (Masuch, 1985; Morçöl, 2010).

Systems dominated by self-balancing loops involve in-built mechanisms that regress to the status quo; disturbances are corrected through the self-balancing patterns (Haraldsson, 2000; Morçöl, 2010; Teisman, van Buuren and Gerrits, 2009). The opposite goes for systems with strong or dominant self-reinforcing loops, in which case originally minor interventions can escalate into large developments. Such inflationary interventions can flip the balance of the system, precipitating outcomes that may be positive or negative with respect to original intent. Sometimes a system develops into a virtuous circle of excellent performance; sometimes a system becomes locked into a vicious cycle and its eventual downfall. Rival explanations for such loops can rest on different social mechanisms, making it crucial that mechanisms be identified in order to reverse or replicate a policy pattern (Mahoney, 2000; Thelen, 1999). The perspective of social mechanisms and causal loops therefore offers a potentially more compelling account of the process of policies "becoming" successes (or failures).

Scholars attentive to the importance of social mechanisms have sorted causal mechanisms in various ways (e.g., Falleti and Lynch, 2009; Mahoney, 2000; Van der Heijden and Kuhlmann, 2017). They deem it important when classifying mechanisms to be attentive to "(1) the level of reality they refer to, (2) their degree of conceptual abstraction, and (3) their assumed scope of application" (Mayntz, 2004, p. 246). Acknowledging the pioneering work by Coleman (1990) and Hedström and Swedberg (1996), in this chapter we adopt the macro-micro relations approach to social science mechanisms as introduced in Chapter 1 of this volume. Within this framework, second-order mechanisms are sets of entities and activities that produce a regular series of state changes in response to the first-order (individual, behavioral) reactions to an activator. Second-order mechanisms are "activated" by individuals" responses to a policy or decision, and generate effects at a level of aggregation above the individual - the institutional, collective, context, or macro level.

We argue that this macro-micro perspective on policy dynamics can be reconciled with the circular causal view of policy systems discussed above by 
recognizing a loop connecting the outcome of second-order mechanisms to the input into first-order (individual) mechanisms - in other words, a feedback loop. Where second-order mechanisms generate change at the macro level that reinforces the value, performance, or legitimacy of a policy instrument or program, this loop is reinforcing. On the other hand, where the effect of the mechanism chain is to undercut the value of the effect a policy instrument or program has on society, this loop would instead represent a self-undermining policy cycle, or even a vicious policy cycle. By now, these dynamics are becoming well-understood (see e.g., Kay, 2006; Patashnik, 2008; Van der Steen et al., 2013). What is less obvious is how dynamic mechanisms affect the degree to which policies are - or come to be seen as - successful. This is what we now turn to.

\section{SUCCESS? FAILURE? ASSESSING POLICY OUTCOMES}

Having recognized the critical role of dynamic mechanisms and complex/circular causality in explanation, the question of interest then arises: when, how, and why do second-order mechanisms produce patterns (either self-reinforcing or self-balancing) that sustain policy success? First, it must be decided what can be called a policy success. Assessment of public policy is necessarily multi-dimensional (Bovens and 't Hart, 1996; Fischer, 1995). At a most fundamental level, both effective performance and public legitimacy are necessary for success. Assessing the performance of a policy refers to evaluating its substantive societal impact of a policy. Assessing its legitimacy requires ascertaining the way it is perceived, experienced and appreciated by stakeholders in public, political and legal arenas. It may be reasonable to expect both types of assessment to yield symmetrical results: high-performing policies will be popular and respected (and will thus have a good chance of becoming self-sustaining). In reality, this is not always the case. Asymmetries can and do emerge. Well-performing policies (e.g., EU membership of Central European countries that has demonstrably contributed to their economic growth) may not for that reason always enjoy broad public and political support (as public opinion data and recent election results in, for example, Poland and Hungary, suggest). Likewise, ineffective or counterproductive policies may nevertheless enjoy strong legitimacy because of their strong fit with dominant value systems and political power structures (US gun "control" policies come to mind). It is an open question what this means for the survival of these policies over time. US gun laws may be an instance of "permanently failing public policy": not delivering core desirables such as harm reduction that are widely supported, but nevertheless politically unassailable. But more often than not, asymmetries between performance and legitimacy may create a context conducive to policy change: policy learning to improve the substantive performance 
of a program while it still enjoys a viable level of political support; political learning to improve an unpopular but fungible policy's reputation and solidify the constellation of stakeholders supporting it; or policy termination to rid the system of programmatic and/or political "train wrecks."

McConnell (2010) reformulated this assessment matrix into a three-dimensional frame, with performance evaluated in programmatic, process, and political terms. We can further refine this three-dimensional view of success. First, programmatic assessment is a "classic" evaluation, focused on explicit policy goals, the theory of change underpinning policy design, and the selection of instruments - all culminating in judgments about the degree to which a policy achieves valuable impacts. This aspect of success is achieved when purposeful and valued action manifests as a direct consequence of the policy instruments. This may entail (1) a well-developed and empirically feasible public value proposition and theory of change underpins the policy; (2) achievement of (or considerable momentum towards) the policy's intended and/or other beneficial social outcomes; and (3) costs/benefits associated with the policy are distributed equitably in society.

Second, process assessment is an evaluation of the extent to which processes of policy design, decision-making and delivery are organized and managed in a way to contribute to both its problem-solving capacity and stakeholders' support for what it tries to achieve and how it tries to do so. This is achieved by thoughtful and effective policy-making practices. This requires (1) a design process that ensures carefully considered choice of policy instruments appropriate to context and in a manner that is perceived to be correct and fair; (2) a decision-making process resulting in firm political commitment and adequate levels of funding, realistic time lines, and administrative capacity; and (3) a delivery process that effectively and adaptively deploys (a mix of) policy instrument(s) to achieve intended outcomes with acceptable costs, and with limited unintended negative consequences.

Last, political assessment evaluates the degree to which policy-makers and agencies involved in driving and delivering the policy can build and maintain fungible political coalitions supporting it, and the degree to which their being associated with it enhances their reputations. In other words, this lens examines both the political requirements for policy success and the distribution of political costs/benefits among the actors involved in it. This is the achievement of stakeholder and public legitimacy for the policy. The components of this dimension of success include the following: (1) a relatively broad and deep political coalition supports the policy's value proposition; (2) that association with the policy enhances the political capital of the responsible policy-makers; and (3) that association with the policy enhances the organizational reputation of the relevant public agencies. 
Embedded in each dimension of these policy assessments (programmatic, process, and political) is temporality - both performance and public and political perceptions of that performance unfold over time (see Bovens and ' $t$ Hart, 1996). Therefore, for a policy to be classified as completely successful, this level of performance must be sustained even in the case of exogenous contextual changes. Such changes may include economic and fiscal ebbs and flows, changes in government composition, demographic and socio-cultural change in target populations, or technological changes in the service delivery environment. In other words, policies that not only endure but also continue to deliver public value in the face of contextual change probably have an adaptive capacity in their modus operandi to sustain the virtuous cycles that made it successful in the first place.

In sum, we define a policy (program, project) as completely successful when (1) it demonstrably produces valued social outcomes; (2) through deliberate design, decision-making, and delivery processes it enhances both its problem-solving capacity and its political legitimacy; and (3) sustains this performance for a considerable period of time, even in the face of changing circumstances (Compton and 't Hart, forthcoming).

Table 11.1 summarizes this dynamic conception of policy evaluation.

\section{HOW SUCCESS (AND FAILURE) HAPPENS: A MECHANISTIC PERSPECTIVE}

With an explicit success (or failure) frame, systematic identification of outcomes of interest in a population of cases becomes possible. Once identified, it is the role of explanatory public policy theory, and the mechanisms specified therein, to account for how policy success outcomes emerge and whether or how it is sustained over time. Minimally, "dynamic" explanation entails time as an independent variable in a model of some phenomenon. Of course, the role of time in public policy is not as simple as this, and dynamic theories are often subject to conceptual ambiguity or under-specification (Grzymala-Busse, 2011; Howlett and Goetz, 2014; Kay, 2006). Importantly, any number of theories may underpin an observed dynamic policy development, hinging on a variety of causal mechanisms.

Falleti and Lynch (2009) compile a (non-exhaustive) list of dynamic mechanisms linking micro processes to macro outcomes. These include: belief formation, rational choice, brokerage, coordination, framing, power reproduction, learning (social learning, political learning), positive feedback (organizational inertia, policy ratchet effect), replacement, layering, conversion, policy drift, increasing returns, and functional consequence. Any of these arguments imply a policy that over time becomes costly to reverse and that has effects at the macro level. Scholars of public policy often identify these mechanisms as rein- 
Table 11.1 Assessing success in public policies

\begin{tabular}{|c|c|c|}
\hline $\begin{array}{l}\text { Programmatic Assessment: } \\
\text { Purposeful and Valued Action }\end{array}$ & $\begin{array}{l}\text { Process Assessment: } \\
\text { Thoughtful and Fair } \\
\text { Policy-making Practices }\end{array}$ & $\begin{array}{l}\text { Political Assessment: } \\
\text { Stakeholder and Public } \\
\text { Legitimacy for the Policy }\end{array}$ \\
\hline $\begin{array}{l}\text { A well-developed and empirically } \\
\text { feasible public value proposition } \\
\text { and theory of change underpins } \\
\text { the policy }\end{array}$ & $\begin{array}{l}\text { The policy process allows } \\
\text { for robust deliberation about } \\
\text { thoughtful consideration of: the } \\
\text { relevant values and interests; the } \\
\text { hierarchy of goals and objectives; } \\
\text { contextual constraints; the (mix } \\
\text { of) policy instruments; and the } \\
\text { institutional arrangements and } \\
\text { capacities necessary for effective } \\
\text { policy implementation }\end{array}$ & $\begin{array}{l}\text { A relatively broad and deep } \\
\text { political coalition supports the } \\
\text { policy's value proposition, } \\
\text { instruments and current results }\end{array}$ \\
\hline $\begin{array}{l}\text { Achievement of (or considerable } \\
\text { momentum towards) the policy's } \\
\text { intended and/or other beneficial } \\
\text { social outcomes }\end{array}$ & $\begin{array}{l}\text { Stakeholders overwhelmingly } \\
\text { experience the making and/or the } \\
\text { delivery of policy as just and fair }\end{array}$ & $\begin{array}{l}\text { Association with the policy } \\
\text { enhances the political capital of } \\
\text { the responsible policy-makers }\end{array}$ \\
\hline $\begin{array}{l}\text { Costs/benefits associated with the } \\
\text { policy are distributed equitably } \\
\text { in society }\end{array}$ & & $\begin{array}{l}\text { Association with the policy } \\
\text { enhances the organizational } \\
\text { reputation of the relevant public } \\
\text { agencies }\end{array}$ \\
\hline $\begin{array}{l}\text { Time } \\
\text { Degree to which programmatic, pro } \\
\text { Degree of convergence in citizens' } \\
\text { Degree to which the policy confers }\end{array}$ & $\begin{array}{l}\text { cess, and political performance is } \mathrm{m} \\
\text { support for the policy's value propo } \\
\text { legitimacy on the broader political } \mathrm{s}\end{array}$ & $\begin{array}{l}\text { intained over time } \\
\text { ition over time } \\
\text { stem }\end{array}$ \\
\hline
\end{tabular}

Source: From Compton and 't Hart (forthcoming).

forcing effects, which create self-sustaining policy regimes to the exclusion of alternative policy institutions (Jervis, 1997; Pierson, 1993, 2000). Feedback mechanisms should account for stability and change in institutions, however, as well as the maintenance of the status quo (Thelen, 1999).

As Weaver (2010, p. 137) rightly points out, it is "equally important to focus on negative policy feedbacks: consequences of policy that tend to undermine rather than reinforce the political, fiscal, or social sustainability of a particular set of priorities." Whether a particular feedback (or dynamic) mechanism will generate reinforcing effects on a policy regime will depend on the balance of competing political, social, and fiscal (positive and negative) influences (Jacobs and Weaver, 2015; Weaver, 2010). In other words, policy mechanisms can also work towards self-subversion of a policy. It is analytically useful, then, to differentiate between mechanisms that produce loops leading to the eventual (programmatic, process and/or political) success of a policy from 
those leading to its failure (again, in one or more of these three dimensions) and potentially its termination (Kirkpatrick, Lester and Peterson, 1999). At the same time, there is one other important distinction to be made. In both theory and practice, we can observe differences between the unforeseen and unplanned activation of such mechanism-driven loops on the one hand, and on the other the deliberate leveraging of such mechanisms in a policy's design or on the part of stakeholders purposefully responding to its enactment.

Figure 11.1 provides an analytical map of the possibilities that emerge when we combine these two distinctions: four types of loops connecting the initiation of a policy to its eventual success or failure, driven by different combinations of first- and second-order mechanisms. The four ideal-typical loops and their driving mechanisms are illustrated by case vignettes drawing from existing studies of major instances of policy success and policy failure.

\begin{tabular}{|c|c|c|c|}
\hline & \multicolumn{2}{|r|}{ Nature } \\
\hline & & Spontaneous-emergent & Designed-intentional \\
\hline \multirow{2}{*}{ 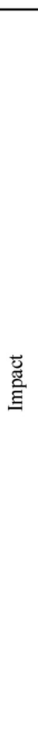 } & $\begin{array}{l}\text { Loops } \\
\text { towards } \\
\text { policy } \\
\text { success }\end{array}$ & $\begin{array}{l}\text { Policy-luck mechanisms } \\
\text { Example: Australian financial } \\
\text { crisis management } \\
\text { - } 1 \text { st order: compliance and } \\
\text { accountability } \\
\text { - 2nd order: learning }\end{array}$ & $\begin{array}{l}\text { Policy-bolstering mechanisms } \\
\text { Example: International anti-money laundering } \\
\text { scheme } \\
\text { 1st order: compliance and reputational } \\
\text { incentives } \\
\text { 2nd order: coordination benefits and } \\
\text { isomorphism }\end{array}$ \\
\hline & $\begin{array}{l}\text { Loops } \\
\text { towards } \\
\text { policy } \\
\text { failure }\end{array}$ & $\begin{array}{l}\text { Policy-erosion mechanisms } \\
\text { Example: Australian home } \\
\text { insulation incentives } \\
\text { 1st order: opportunistic } \\
\text { competition } \\
\text { 2nd order: negative image } \\
\text { building and framing }\end{array}$ & $\begin{array}{l}\text { Policy-sabotage mechanisms } \\
\text { Example: UK Poll Tax and self- } \\
\text { undermining feedback } \\
\quad 1 \text { st order: strategic (non-)compliance } \\
\text { 2nd order: emergent losses and counter- } \\
\text { mobilization }\end{array}$ \\
\hline
\end{tabular}

Figure 11.1 Linking social mechanisms to policy success and failure 


\section{Policy-bolstering Mechanisms}

When societal problems spill over geographic, policy-domain, or task-related jurisdictional boundaries, collaboration between political entities can be beneficial, if not necessary. Solving some social problems requires cooperation. International money laundering is one such problem. The proliferation of anti-money laundering standards in the past 30 years reflects a diverse set of policy goals related to corruption, drug trafficking, and more recently, terrorism (Tsingou, 2010). Initiated by the EU and the US in 1989, the Financial Action Task Force published a list of 40 best practices for financial supervision and regulation, law enforcement guidelines, and protocols for international cooperation that are now adopted by more than 170 countries worldwide (Drezner, 2005; Sharman, 2008). The EU and the US implemented these recommendations quickly out of clear self-interest as the largest beneficiaries of cooperation, and other developed (OECD) members soon followed (Drezner, 2005).

As the problem of offshore financial centers evolved, the benefits of collaboration in the coordination of national and transnational measures to prevent future banking scandals grew, and the US and EU put effort towards persuasion and inducements (along with the threat of penalizing "countermeasures" for non-participants) to ensure widespread international policy harmonization (Drezner, 2005). Although the process of harmonization by less-developed countries did require coercive power on the part of the EU and the US (Sharman, 2008), potential gains from collaboratively co-produced coordinated money laundering regulation reinforce the survival of an existing set of standards. Changing a policy regime that has so been forged would require the coordination of all current participants (more than 170), thereby incurring large transaction costs. In this case, collaborative processes combined with compliance and reputational incentives (first-order mechanisms) to yield coordination benefits and isomorphism. Policy lock-in eventually emerged through a positive feedback loop fueled by these mechanisms. Once an initial advantage was gained (a set of standards adopted by some), benefits increased with each additional adoption, and the cost of policy change thereby increased (Pierson, 1993, 2000).

Policies designed to address problems that cross borders - like money laundering - will be most effective where regimes across jurisdictions are harmonized. Once trust-building processes started to generate on-the-ground harmonization of anti-money laundering measures and practices, this enhanced programmatic success because defection from the shared regime could severely limit achievement of beneficial social outcomes. Furthermore, the now extensive research on collaborative governance suggests that a careful institutional design, facilitative leadership and the emergence of interpersonal trust and shared understandings of commonly faced challenges in collaborative 
settings where actors that previously failed to coordinate their actions or even competed against one another, can generate an ever stronger commitment to the collaborative process itself, which in turn increases the chances of the collaboration producing valuable outcomes and sustaining itself over time (Ansell and Gash, 2008; Emerson, Nabatchi and Balogh, 2012). In this instance, smart institutional design and effective facilitative leadership (Ansell and Gash, 2012) combined to overcome initial commitment problems. As in many other instances of effective collaborative governance, much depended on continued and painstaking micro-level interactions for the macro-level benefits of policy coordination to be achieved.

\section{Policy-luck Loops}

Australia was one of few OECD economies not to experience a major breakdown in its financial institutions during the Global Financial Crisis of 2008-09. Programmatic success lay in the non-occurrence of events and consequences that the policy-makers keenly sought to avoid. The four major Australian banks all avoided the worst of the Global Financial Crisis. Aggregate pre-tax profit at these four banks fell only marginally from A \$6.3 billion in 2007 to A \$5.1 billion in 2008 and A \$5.4 billion in 2009. None of the four banks had its credit rating downgraded; indeed, by late 2009, four of the nine global banks with an AA credit rating from Standard \& Poor's were Australian (RBA, 2009 , p. 25). No major bank went under. No panic occurred in local financial markets, although bank share prices suffered for a period. Banks kept lending, money kept flowing through the economy. There were no mass foreclosures of homes whose mortgages could no longer be paid. Consumer and business confidence only suffered short-lived and minor dents.

In political terms, the main thrust of the regulatory, monetary, and fiscal policy measures taken prior and in response to the crisis was supported by a broad coalition consisting of the federal cabinet, the Treasury department and the Council of Financial Regulators (which included, besides the Treasury, the Reserve Bank of Australia (RBA), the Australian Prudential Regulation Authority (APRA), the Australian Securities and Investments Commission (ASIC), the Business Council of Australia, and, importantly, a large proportion of the Australian public). The strong performance of the financial system in these turbulent conditions certainly enhanced the standing, including the international reputation, of all the regulatory institutions involved.

In process terms, a key factor was that Australia's major banks had remained, on the whole, focused on traditional banking practices. In particular, the big Australian banks did not become heavily involved in highly leveraged financial trading in "toxic" mortgage-backed assets emanating from the US. The two largest banks, Westpac and the Commonwealth, eschewed trading 
in US-originated mortgage-backed securities altogether, and the others had comparatively limited exposure.

The Australian banks behaved so differently from their counterparts around the globe because of the interplay between local market dynamics (local banks were making strong profits in traditional mortgage markets); competition policy (which essentially outlawed the takeover market for the big banks and thus reduced competitive pressure on the banks from hostile takeovers, a key driver of the bank behavior and risk-taking in the crisis-hit banks overseas markets); and "near-miss" experiences of, in retrospect fortuitously timed, earlier macro- (the 1997 Asian recession) and micro-economic (the 2001 collapse of Australian financial giant HIH) disturbances. These had prompted compliance and accountability (first-order mechanisms): not only were regulatory policies and the institutional structure of prudential regulation firmed up, but the social ties between the key players in the regulatory community were also strengthened. In parallel, and equally fortuitously, the coincidental combination of personalities and role conceptions of the key regulatory players - all hailing from non-elite social backgrounds, with a no-nonsense, grounded attitude fostered mutual trust so pivotal at the point of crisis. This in turn produced institutional learning (second-order mechanism) resulting in higher alertness, stronger and swifter policy consensus, and hence more effective prudential crisis prevention practices when the 2008 global crash came along. None of this was designed or even envisaged, but it worked when it needed to (Bell and Hindmoor, forthcoming).

\section{Policy-erosion Loops}

It seemed like a smart move, one that would help a dramatic higher-order macro-economic policy become programmatically effective and that at the same time would symbolize the governing Labor Party's political commitment to progressive environmental policies: the home insulation subsidies scheme launched by the Australian federal government in 2009. The scheme was part of a massive A $\$ 42$ billion stimulus package seeking to give the hitherto buoyant Australian economy a soft landing rather than a hard recession as the Global Financial Crisis crippled trade, investment and growth around the OECD world. Up to 2.7 million homes were envisaged to receive free ceiling insulation. Because speed was considered paramount - money needed to flow into the real economy as soon as possible to prevent recession - the process of making this policy work occurred under immense time pressure and was described by participants as "hectic," "chaotic." Programmatically, what this sudden announcement did was not just to put so-called "pink bats" (after the color of the commonly used insulation sheets used) under many Australian roofs, but to change the prevailing market equilibrium in this sector overnight 
as citizen uptake of the scheme was instant and massive. As a result, the capacity of existing suppliers was outstripped, and a flood of new operators entered the now lucrative business (opportunistic response to competitive incentives - first-order mechanism). Many of the new operators were, however, uncertified and unqualified and a spate of fires in recently insulated homes resulted. Furthermore, when within the space of weeks four fatalities among electrician apprentices occurred during installations, there was media carnage and the political failure of the scheme was ensured (negative image building and framing - second-order mechanism). Damning investigation reports ensued, the responsible minister was moved on, and a costly effort to review all recently insulated roofs across the country had to be undertaken. The scheme, needless to say, was rapidly terminated (Lewis, 2012).

\section{Policy-sabotage Loops}

Before 1985, the concept of a Poll Tax to finance local government seemed far-fetched in the UK (John, 1999). The policy instrument was so uncommon in fact, that it had only been tried three times before: in Papua New Guinea, Guinea-Bissau, and in England in the Middle Ages (ibid.). And yet, in 1990, the individual Poll Tax was chosen over a list of other debated alternatives. Supporters successfully pushed the proposal through Parliament by capitalizing on a political environment that rewarded risk-taking in policy-making, and clever framing to reflect in-vogue ideas of fiscal roll-backs and efficiency (Cullis, Jones and Morrissey, 1993; John, 1999). Within three years, however, the policy proved "disastrous" (politically, procedurally, and programmatically) and was dismantled (Smith, 1991). The Poll Tax faced a host of implementation problems, high local taxes and massive unpopularity, and by 1991 the tax's main defender, Prime Minister Margaret Thatcher, fell from office (John, 1999). Poorly conceived and implemented, yes, but the final blow to the policy was the public uproar and strategic avoidance behavior that reinforced negative feedback, ensuring the policy's quick end. The case of the short-lived UK Poll Tax demonstrates how initially spontaneous and (micro-level) resistance to a policy can be purposefully harnessed as a source of ever stronger negative feedback loops, and transformed into not only an effective policy termination campaign but also inflict fatal political damage on the policy chief political architect (macro level) (Butler, Adonis and Travers, 1995).

That the policy failed is clear - it existed for only three years before being replaced with the now known Council Tax in 1993. Programmatically, the policy failed to deliver on the promises of efficiency and improved accountability. Complexities in the UK's system of local government through a combination of individual taxes and block grants from the central government obscured the potential gains in local accountability for spending (John, 1999). 
The policy also failed procedurally. Difficulties in creating an accurate register of adults and adequately addressing civil liberties issues greatly hampered implementation (ibid.). Most crucially, however, the policy was a political failure. As a consequence of central government cutbacks and local spending rises, most adults experienced a steep tax hike in the first year, which only increased perceptions that the policy was unfair and fueled public and elite protest over the policy (ibid.).

Public resistance to the bill manifested in more than negative public opinion, however. Non-compliance spread, as individuals craftily avoided the new tax obligation (Butler et al., 1995). Deliberate individual responses (first-order mechanisms) to the policy prevented efficient or effective collection of the tax, which only further fed the political coalition opposed to the policy. The counter-mobilization (a second-order mechanism) in favor of termination increased the cost of policy persistence to the incumbent government - in terms of political capital and administrative cost. The coalition incentivized by the policy was not of the self-reinforcing type with positive (political) feedback (i.e., Pierson, 1993, 2000), this was a self-undermining process (Jacobs and Weaver, 2015). The design and implementation of the Poll Tax reshaped interests in a way that made the policy unsustainable and contributed to the Conservatives' reshuffle and John Major's replacement of Thatcher.

\section{EXPLAINING AND ACHIEVING POLICY SUCCESS THROUGH SOCIAL MECHANISMS: MOVING FORWARD}

In this chapter we have argued that understanding of policy successes and failures can benefit from an analytical approach that is both dynamic and mechanistic. To move forward the study of public policy success beyond description and in the direction of policy design, researchers should endeavor to incorporate insights from the study of policy mechanisms into explanations of the origins of very high-performing (in programmatic, process, and political terms) as well as low-performing policies and programs. Viewing policy processes as circular loops driven or mediated by social mechanisms can help us to account for not just instances of success but also for variations in degrees of success (and failure) in populations of cases, for example within particular sectors but across local, state or national jurisdictions. A four-step approach to researching such populations once identified (i.e., road-safety, anti-smoking, anti-obesity, or climate adaptation water management programs) would be required:

1. Program assessment - using the three-dimensional schema of programmatic, process, and political evaluation outlined in this chapter.

2. Selecting two samples of "extreme" (most-different) cases: high-performing and low-performing programs. 
3. Within-case intensive process description (i.e., using critical incident analysis).

4. Reconstructing critical pathways (both linear and loop-like) to the observed outcomes and explaining these pathways in terms of the (first- and second-order) social mechanisms at work.

Moreover, through Figure 11.1 and the brief examples above, we hope to illustrate the value of mechanistic-thinking to the study of policy success. Second-order mechanisms explain how micro-level changes (in perceptions, attitudes, and behavior in response to policy interventions) link to meso- and macro-level changes (in incentive structures, norms, and expectations), which have consequences that may reinforce and/or undermine public policy performance (in programmatic, process, and political terms). In Figure 11.1 we further make the case for distinguishing between the spontaneous, inadvertent emergence of such success- or failure-enhancing mechanisms and loops, and their deliberate incorporation in the designs and political strategies of policy-makers and other influential stakeholders.

A combination of population-level and intensive single or small- $n$ analyses of policy failures and policy successes can help us identify the extent to which these outcomes are triggered by distinct (combinations of) mechanisms and loops - as implied in Figure 11.1 - and to which one and the same mechanism may trigger both success-enhancing and failure-enhancing loops. One particularly compelling question that emerges from this is whether and how mechanistic-thinking can inform policy design. Can first- and second-order mechanisms be purposefully predicted, designed, harnessed, and exploited by policy-makers and stakeholders to produce policy success (or failure)? Though we imply this to be the case in Figure 11.1 and two of the examples presented earlier, it is by no means definitively demonstrated. What can mechanistic thinking contribute to inform policy-makers" "theories of change" as they go about seeking not only to create policies that "work" but that also endure and institutionalize over time, and conversely to inform stakeholders" "theories of obstruction" as they endeavor to create the conditions for policy failure and termination?

\section{NOTE}

1. Parts of this section were adapted from Van der Steen et al. (2015, pp. 325-6), with kind permission of Paul 't Hart's co-authors.

\section{REFERENCES}

Ansell, C. and A. Gash (2008), "Collaborative governance in theory and practice," Journal of Public Administration Research and Theory, 18(4), 543-71. 
Ansell, C. and A. Gash (2012), "Stewards, mediators, and catalysts: Toward a model of collaborative leadership," Innovation Journal, 17(1), 1-21.

Ayres, S. (ed.) (2014), Rethinking Policy and Politics: Reflections on Contemporary Debates in Policy Studies, Bristol: Policy Press.

Bell, S. and A. Hindmoor (forthcoming), "Avoiding the Global Financial Crisis in Australia: A policy success?," in J. Luetjens, M. Mintrom and P. 't Hart (eds), Successful Public Policy: Lessons from Australia and New Zealand, Canberra: ANU Press.

Bovens, M. and P. 't Hart (1996), Understanding Policy Fiascoes, New Brunswick, NJ: Transaction.

Bovens, M. and P. 't Hart (2016), "Revisiting the study of policy failures," Journal of European Public Policy, 1763(August), 0-14.

Bovens, M., P. 't Hart and B.G. Peters (eds) (2001), Success and Failure in Public Governance: A Comparative Analysis, Cheltenham, UK and Northampton, MA, USA: Edward Elgar Publishing.

Butler, D., A. Adonis and T. Travers (1995), Failure in British Government: The Politics of the Poll Tax, Oxford: Oxford University Press.

Cavana, R.Y. and E.D. Mares (2004), "Integrating critical thinking and systems thinking: From premises to causal loops," System Dynamics Review, 20(3), 223-35.

Chapman, J. (2004), System Failure: Why Governments Must Learn to Think Differently, 2nd edition, London: Demos.

Coleman, J. (1990), Foundations of Social Theory, Cambridge, MA: Harvard University Press.

Collander, D. and R. Kupers (2014), Complexity and the Art of Public Policy: Solving Society's Problems from the Bottom Up, Princeton, NJ: Princeton University Press.

Compton, M. and P. 't Hart (eds) (forthcoming), Great Policy Successes: How Governments Get It Right in a Big Way at Least Some of the Time, Oxford: Oxford University Press.

Cullis, J.G., P.R. Jones and O. Morrissey (1993), "The charge of the tax brigade: A case study of government failure and tax reforms," European Journal of Political Economy, 9(3), 407-25.

De Roo, G., J. van Wezemael and J. Hillier (eds) (2012), Complexity and Planning: Systems, Assemblages and Simulations, Farnham: Ashgate.

Deutsch, K.W. (1963), The Nerves of Government: Models of Political Communication and Control, New York: The Free Press.

Drezner, D.W. (2005), "Globalization, harmonization, and competition: The different pathways to policy convergence," Journal of European Public Policy, 12(5), 841-59. 
Emerson, K., T. Nabatchi and S. Balogh (2012), “An integrative framework for collaborative governance," Journal of Public Administration Research and Theory, 22(1), 1-29.

Falleti, T.G. and J.F. Lynch (2009), "Context and causal mechanisms in political analysis," Comparative Political Studies, 42(9), 1143-66.

Fischer, F. (1995), Evaluating Public Policy, Chicago, IL: Nelson Hall.

Forrester, J.W. (1961), Industrial Dynamics, Cambridge, MA: MIT Press.

Givel, M. (2010), "The evolution of the theoretical foundations of punctuated equilibrium theory in public policy," Review of Policy Research, 27(2), 187-98.

Glazer, A. and L.S. Rothenberg (2001), Why Government Succeeds and Why It Fails, Cambridge, MA: Harvard University Press.

Grzymala-Busse, A. (2011), "Time will tell? Temporality and the analysis of causal mechanisms and processes," Comparative Political Studies, 44(9), 1267-97.

Hall, P. (1982), Great Planning Disasters, Berkeley, CA: University of California Press.

Haraldsson, H.V. (2000), Introduction to Systems and Causal Loop Diagrams: System Analysis Course, Lund: Lund University.

Hedström, P. and R. Swedberg (1996), "Social mechanisms," Acta Sociologica, 39(3), 281-308.

Howlett, M. and K.H. Goetz (2014), "Introduction: Time, temporality and timescapes in administration and policy," International Review of Administrative Sciences, 80(3), 477-92.

Howlett, M. and J. Rayner (2006), "Understanding the historical turn in the policy sciences: A critique of stochastic, narrative, path dependency and process-sequencing models of policy-making over time," Policy Sciences, 39(1), 1-18.

Jacobs, A.M. and R.K. Weaver (2015), "When policies undo themselves: Self-undermining feedback as a source of policy change," Governance, 28(4), 441-57.

Jervis, R. (1997), System Effects: Complexity in Political and Social Life, Princeton, NJ: Princeton University Press.

John, P. (1999), "Ideas and interests; agendas and implementation: An evolutionary explanation of policy change in British local government finance," British Journal of Politics and International Relations, 1(1), 39-62.

Jordan, A. and E. Matt (2014), "Designing policies that intentionally stick: Policy feedback in a changing climate," Policy Sciences, 47(3), 227-47.

Kay, A. (2006), The Dynamics of Public Policy: Theory and Evidence, Cheltenham, UK and Northampton, MA, USA: Edward Elgar Publishing.

King, A. and I. Crewe (2014), The Blunders of Our Governments, London: Oneworld Publications. 
Kirkpatrick, S.E., J.P. Lester and M.R. Peterson (1999), “The policy termination process: A conceptual framework and application to revenue sharing," Review of Policy Research, 16(1), 209-238.

Laitin, D.D. and A. Wildavsky (1988), "Political culture and political preferences," American Political Science Review, 82(2), 589-97.

Lane, D.C. (2008), "The emergence and use of diagramming in system dynamics: A critical account," Systems Research and Behavioral Science, 25, 3-23.

Leeuw, F.L. (2008), "Gedragsmechanismen achter overheidsinterventies en rechtsregels" [Behavioral mechanisms behind government interventions and legal rules], lecture, Intreerede Universiteit Maastricht.

Lewis, C. (2012), "A recent scandal: The Home Insulation Program," in C. Lewis and K. Dowding (eds), Ministerial Careers and Accountability in the Australian Commonwealth Government, pp. 153-76, accessed 27 October 2108 at http://press-files.anu.edu.au/downloads/press/p191121/pdf/ch082.pdf.

Maani, K.E. and R.Y. Cavana (2000), Systems Thinking and Modelling: Understanding Change and Complexity, Auckland: Pearson Education (NZ).

Mahoney, J. (2000), "Path dependence in historical sociology," Theory and Society, 29(4), 507-48.

Maruyama, M. (1963), “The second cybernetics: Deviation-amplifying mutual causal processes," American Scientist, 51(2), 164-79.

Masuch, M. (1985), "Vicious circles in organizations," Administrative Science Quarterly, 30(1), 14-33.

Mayntz, R. (2004), "Mechanisms in the analysis of social macro-phenomena," Philosophy of the Social Sciences, 34(2), 237-59.

McConnell, A. (2010), Understanding Policy Success: Rethinking Public Policy, Basingstoke: Palgrave Macmillan.

Merali, Y. and P. Allen (2011), "Complexity and systems thinking," in P. Allen, S. Maguire and B. McKelvey (eds), The Sage Handbook of Complexity and Management, London: Sage, pp. 31-52.

Morçöl, G. (2010), "Reconceptualizing public policy from the perspective of complexity theory," Emergence: A Journal of Complexity Issues in Organizations and Management, 12, 52-60.

Patashnik, E.M. (2008), Reforms at Risk: What Happens after Major Policy Changes Are Enacted, Princeton, NJ: Princeton University Press.

Peirce, W. (1981), Bureaucratic Failure and Public Expenditure, New York: Academic Press.

Perrow, C. (1984), Normal Accidents, New York: Basic Books.

Peters, B.G. (2015), An Advanced Introduction to Public Policy, Cheltenham, UK and Northampton, MA, USA: Edward Elgar Publishing.

Peters, B.G., J. Pierre and D.S. King (2005), "The politics of path dependency: Political conflict in historical institutionalism," The Journal of Politics, 67(4), 1275-300. 
Pierson, P. (1993), "When effect becomes cause: Policy feedback and political change," World Politics, 45(4), 595-628.

Pierson, P. (2000), "Increasing returns, path dependence, and the study of politics," The American Political Science Review, 94(2), 251-67.

RBA (Reserve Bank of Australia) (2009), Financial Stability Review, March.

Richardson, G.P. (1986), "Problems with causal-loop diagrams," System Dynamics Review, 2(2), 158-70.

Richardson, G.P. (1991), Feedback Thought in Social Science and Systems Theory, Waltham, MA: Pegasus Communications.

Richmond, B. (1993), "Systems thinking: Critical thinking skills for the 1990s and beyond," System Dynamics Review, 9(2), 113-33.

Sabatier, P. and C. Weible (eds) (2014), Theories of the Policy Process, 3rd edition, Boulder, CO: Westview Press.

Schuck, P.H. (2014), Why Government Fails So Often, and How It Can Do Better, Princeton, NJ: Princeton University Press.

Senge, P.M. (1990), The Fifth Discipline: The Art and Practice of the Learning Organization, London: Century Business.

Sharman, J.C. (2008), "Power and discourse in policy diffusion: Anti-money laundering in developing states," International Studies Quarterly, 52(3), 635-56.

Sieber, S.D. (1981), Fatal Remedies: The Ironies of Social Intervention, New York: Plenum.

Smith, P. (1991), "Lessons From the British Poll Tax disaster," National Tax Journal, 44(4), 421-37.

Steinbruner, J.D. (1974), The Cybernetic Theory of Decision: New Dimensions of Political Analysis, Princeton, NJ: Princeton University Press.

Teisman, G., A. van Buuren and L. Gerrits (2009), Managing Complex Governance Systems, New York: Taylor \& Francis.

Thelen, K. (1999), "Historical institutionalism in comparative politics," Annual Review of Political Science, 2(1), 369-404.

Toole, T.M. (2005), "A project management causal loop diagram," in F. Khosrowshahi (ed.), 21st Annual ARCOM Conference, 7-9 September, 2005, SOAS, London.

Tsingou, E. (2010), "Global financial governance and the developing anti-money laundering regime: What lessons for international political economy?," International Politics, 47(6), 617-37.

Van der Heijden, J. and J. Kuhlmann (2017), "Studying incremental institutional change: A systematic and critical meta-review of the literature from 2005 to 2015," Policy Studies Journal, 45(3), 535-54.

Van der Steen, M., J. Scherpenisse, M. van Twist and P. 't Hart (2015), "How to see failure: Attempts by the Inspectorate of Education to detect and disarm failure in Dutch education policy," Public Policy and Administration, 30(3-4), 320-41. 
Van der Steen, M., M. van Twist, M. Fenger and S. Le Cointre (2013), "Complex causality in improving underperforming schools: A complex adaptive systems approach," Policy and Politics, 41(4), 551-67.

Weaver, K. (2010), "Paths and forks or chutes and ladders? Negative feedbacks and policy regime change," Journal of Public Policy, 30(2), 137-62. 